\title{
Genetic Diversity and Biocontrol of Rosellinia necatrix Infecting Apple in Northern Italy
}

Luca Pasini, Department of Sustainable Agro-ecosystems and Bioresources, Research and Innovation Centre; Daniele Prodorutti, Centre for Technology Transfer; Sandro Pastorelli, Department of Sustainable Agro-ecosystems and Bioresources, Research and Innovation Centre; and Ilaria Pertot, Department of Sustainable Agro-ecosystems and Bioresources, Research and Innovation Centre, Fondazione Edmund Mach, Via E. Mach 1, 38010 S. Michele all'Adige, TN, Italy

\begin{abstract}
Pasini, L., Prodorutti, D., Pastorelli, S., and Pertot, I. 2016. Genetic diversity and biocontrol of Rosellinia necatrix infecting apple in northern Italy. Plant Dis. 100:444-452.

The soilborne fungus Rosellinia necatrix is the causal agent of white root rot disease on numerous plant species, including apple, which, together with the ability to survive in soil for long periods, makes this pathogen difficult to control. To understand the origins of pathogen infestation, a survey of diseased apple orchards in the northeast of Italy was conducted and 35 isolates of $R$. necatrix were characterized with intersimple sequence repeat markers. High genetic heterogeneity among the collected isolates suggested multiple preexisting sources of inoculum and not

movement of infected soil or plant material from a single source. Greenhouse trials confirmed that, as with some other crops, soil water content and temperature were the main factors influencing infection of apple plants, while organic fertilizers and the incorporation of apple wood residues were less important. The efficacy of Trichoderma atroviride SC1 as a biocontrol agent against $R$. necatrix greatly depended on the timing of application. It reduced white root rot incidence on apple seedlings only if treatment was applied at least 1 week before planting.
\end{abstract}

The soil-inhabiting ascomycete Rosellinia necatrix Berl. ex Prill. is the causal agent of white root rot disease on a wide range of plant species. The fungus is distributed worldwide in temperate, subtropical, and tropical areas. To date, the Systematic Botany and Mycology Laboratory of the United States Department of Agriculture reports a list of 437 host plants, including mainly woody plants (fruit trees, nut tree crops, and forest trees) but also herbaceous species (United States Department of Agriculture FUNGAL database; http://nt.ars-grin.gov/ fungaldatabases/index.cfm). Many of the host plants are of significant economic importance (e.g., apple, pear, grape, orange, olive, avocado, and coffee) (Arakawa et al. 2002; Colatruglio et al. 2006; Faretra and Frisullo 2002; López-Herrera 1998; Pliego et al. 2012; Sztejnberg 1990).

The entire life cycle of $R$. necatrix occurs in soil. The pathogen spreads by root-to-root contact or by growth of mycelial strands through soil. The infection process has been carefully described (Pliego et al. 2009), although the role and epidemiological significance of the different spore types formed by $R$. necatrix (chlamydospores, conidiospores, and ascospores) remains unclear (Pérez-Jiménez 2006; Pliego et al. 2012). The infection on apple (Malus $\times$ domestica Borkh.) occurs after ecotrophic mycelium has colonized the root surface (Tourvieille de Labrouhe 1982). Root penetration occurs through lenticels or wounds, or directly from a penetration sclerotium. After infection, mycelia invade the xylem, where the release of toxins is followed by aerial symptoms of decreased vigor and wilting (Pliego et al. 2009). Advanced infections show white, cottony mycelium on the infected root surface and a general rotting of roots. Characteristic white mycelial fans occur under the bark of the roots (Pérez-Jiménez 2006).

Corresponding author: L. Pasini, E-mail: pasini-luca@libero.it

L. Pasini and D. Prodorutti contributed equally to this work

*The $\boldsymbol{e}$-Xtra logo stands for "electronic extra" and indicates that three supplementary figures are published online.

Accepted for publication 12 August 2015.

http://dx.doi.org/10.1094/PDIS-04-15-0480-RE

(C) 2016 The American Phytopathological Society
Due to the ability of $R$. necatrix to live as a saprophyte (PérezJiménez 2006), it can survive in soil for long periods on woody debris (Nakamura et al. 2000; Pérez-Jiménez 2006). Under laboratory conditions, the optimal temperature range for $R$. necatrix growth is between 22 and $25^{\circ} \mathrm{C}$ (Anselmi and Giorcelli 1990; Mantell and Wheeler 1973). Soil water content near field capacity has been shown to promote pathogen growth in loose soil on poplar cuttings (Anselmi and Giorcelli 1990) and in bulb fields (Mantell and Wheeler 1973). In vitro optimal pH is between 4 and 9 (Makambila 1978), while soil $\mathrm{pH}$ between 6 and 8 has been found to be favorable for pathogen attack on poplar (Anselmi and Giorcelli 1990). Conversely, temperatures below 5 or above $32^{\circ} \mathrm{C}$, low oxygen levels (Anselmi and Giorcelli 1990; Mantell and Wheeler 1973), exposure to light (Anselmi and Giorcelli 1990; Makambila et al. 1976), and clay soil (Khan 1959) all strongly inhibit mycelial development.

Italy is the fifth producer of apple in the world, with almost two million tons produced per year (www.wapa-association.org). In northeastern Italy, the primary apple-growing area, first reports of the white root rot occurred in the early 1980s and 1990s in Trentino-Alto Adige (TAA) and the Friuli Venezia Giulia (FVG) regions, respectively. Over recent years, disease incidence has been slowly but continuously increasing (Chini and de Clauser 1983; Unità Frutticoltura Fondazione E. Mach, personal communication) but is not commonly higher than 5 to $10 \%$ (Chini and de Clauser 1983). However, when dead trees are replaced with new trees, they normally die within a few months.

Although genetic and molecular tools to identify and quantify the pathogen have been developed (Ruano-Rosa et al. 2007; Schena et al. 2002; Schena and Ippolito 2003), the ecology and epidemiology of white root rot remains poorly understood (Pliego et al. 2012), especially on apple. Most importantly, the sources of inoculum (local or introduced) and cultural practices and soil factors that exacerbate or suppress infection remain undetermined. Moreover, methods to ameliorate know inoculum foci within orchards have received little research effort. The wide spectrum of plant hosts and the ability to survive on organic matter and root debris in the soil make this pathogen very difficult to control once it has been established in an orchard. Because chemical control is ineffective (Schena et al. 2008) and solarization is applicable only locally, where climatic conditions are favorable (Freeman et al. 1990; López-Herrera et al. 1999; Sztejnberg et al. 1987), control of the disease is almost wholly reliant on preventive measures. Very few studies have been carried out on 
biocontrol of R. necatrix (Pliego et al. 2012). Trichoderma spp. are well known for their high mycoparasitic properties and have given encouraging results against $R$. necatrix (Freeman et al. 1986; Ruano-Rosa and López-Herrera 2009; Ruano-Rosa et al. 2014). In particular, Trichoderma atroviride $\mathrm{SC} 1$, isolated in northern Italy from decayed hazelnut wood, has been shown to have high persistence in soil (Longa et al. 2009) or in organic matter (Pellegrini et al. 2014) and can successfully reduce the incidence of Armillaria spp. (Pellegrini et al. 2014; Pertot et al. 2008), which have behavior similar to that of $R$. necatrix.

The aim of this work was to gain knowledge that could be used to give advice to growers on how to prevent the spread and build-up of the disease in apple orchards through the employment of the best agronomic practice and biocontrol methods. Specifically, we (i) determined the potential sources of $R$. necatrix inoculum for apple orchards by studying the genetic diversity based on intersimple sequence repeat (ISSR) among isolates collected from the apple-growing area in northeast Italy; (ii) assessed the role of temperature, soil water content, incorporation of apple-pruning residues, and use of organic fertilizer in promoting white root rot; and (iii) identified the best timing of treatments with biocontrol agent $T$. atroviride $\mathrm{SC} 1$ to reduce the incidence of reinfection in known $R$. necatrix inoculum centers.

\section{Materials and Methods}

Survey of $\boldsymbol{R}$. necatrix from apple roots. Between 2009 and 2012, a survey to identify orchards potentially infected by $R$. necatrix was conducted, first by interviewing crop advisors or local growers in northeastern Italy. Potentially infected orchards were inspected for symptoms of white root rot. Symptoms included stunted aerial growth, chlorotic and wilted leaves, death of shoots and branches, and trees easily uprooted, with signs of white cottony mycelium and mycelial strands on rotted roots. Within each orchard, at least one sample of root tissue with white cottony mycelium was collected from each infection patch. Each sample was individually contained in a plastic bag and transported in an ice chest to the laboratory for the isolation of putative pathogens. For each sample site, information was collected on cultivar and rootstock, nursery of origin, the year of transplanting, the previous crops, the types of crops or vegetation in the proximity, the year in which symptoms where first observed, the incidence of symptomatic plants, soil texture, and the agronomical practices carried out before replanting the orchard (Table 1).

R. necatrix was isolated from root samples following the method of Ruano-Rosa et al. (2007), with some modifications. Briefly, soil was gently removed, roots were carefully washed with tap water, surface sterilization was carried out using sodium hypochlorite $(0.5 \%$ solution) for $3 \mathrm{~min}$, and roots were rinsed twice with distilled water and then placed in a humid chamber at $20 \pm 2{ }^{\circ} \mathrm{C}$ in the dark to induce the development of the white cottony mycelium. After 7 days of incubation, white, aerial mycelia were transferred under sterile conditions to potato dextrose agar (PDA; Oxoid, Basingstoke Hampshire, UK) amended with streptomycin sulfate (Sigma-Aldrich, St. Louis) at $0.05 \mathrm{~g} /$ liter. Cultures were kept at $24^{\circ} \mathrm{C}$ in the dark and $R$. necatrix colonies were identified initially under a light microscope by the presence of the typical pear-shaped swellings adjacent to septa (Francis 1985). Subcultures were obtained by transferring the growing hyphae onto fresh PDA and incubated as above.

DNA extraction, identification, and ISSR analysis. $R$. necatrix isolates were grown in the dark at $24^{\circ} \mathrm{C}$ for 10 days on PDA covered with a sterile cellophane sheet (Eurofilms, Varese, Italy) to facilitate the harvest of mycelium and avoid collection of the culture substrate. Mycelium on the cellophane sheet was collected under a sterile hood, lyophilized, and ground in a homogenizer (Mixer Mill MM 200; Retsch GmbH, Haan, Germany). Total DNA was extracted from homogenized mycelium with the NucleoSpin Plant II kit (MechereyNagel, Düren, Germany), used according to the manufacturer's instructions. The amount of DNA was measured using a NanoDrop 8000 spectrophotometer (Thermo-Fisher Scientific, Waltham, MA), and all samples were diluted to a final concentration of $5 \mathrm{ng} / \mu \mathrm{l}$.

Molecular identification of isolates was subjected to conventional polymerase chain reaction (PCR) with the $R$. necatrix-specific primers $\mathrm{R} 2$ and R8 (Schena et al. 2002), which amplify one region of the internal transcribed spacer (ITS) ribosomal DNA. PCR was conducted in a Biometra Thermocycler TProfessional (Biometra, Göttingen, Germany). Each reaction volume of $25 \mu \mathrm{l}$ contained $1 \times$ PCR buffer, $2.5 \mathrm{mM}$ $\mathrm{MgCl}_{2} ; \mathrm{dNTPs}$, each at $200 \mu \mathrm{M}$; primers, each at $0.4 \mu \mathrm{M} ; 1 \mathrm{U}$ of DNA Taq polymerase (Fermentas; Thermo-Fisher Scientific); and $1 \mu \mathrm{l}$ of template DNA. The PCR products were analyzed by electrophoresis in $1.5 \%$ agarose gel. The Gene Ruler 100-bp DNA ladder plus (Thermo-Fisher Scientific) was used as a molecular weight marker.

Analysis of genetic diversity among $R$. necatrix isolates was performed using four ISSR primers (ISSR1, ISSR2, ISSR4, and ISSR5) developed by Armengol et al. (2010). PCR amplifications were carried out in a Biometra Thermocycler TProfessional (Biometra) as described by Armengol et al. (2010), using 0.5 U of DreamTaq DNA polymerase (Fermentas; Thermo-Fisher Scientific). PCR products were visualized as described above; MassRuler DNA Ladder Mix (Ready-to-Use, 80 to 10,000 bp; Thermo-Fisher Scientific) was used as a molecular weight marker. Digitized images of the four gels were analyzed by BioNumerics software (version 6.0; Applied Maths NV, Sint-Martens-Latem, Belgium), which converts, normalizes, and analyzes the band patterns. A binary data set was created for each gel, scoring " 1 " to indicate presence and " 0 " for absence of the bands. Similarity among isolates was evaluated for each ISSR pattern using the unweighted pair-group method with arithmetic mean clustering method and the band-based Dice coefficient (Dice 1945) and represented as a combined dendrogram based on the average of similarities from all ISSR patterns. Two $R$. necatrix isolates (DN-53925-618 and DN-10_02392-645 isolated from Olea europea and Prunus persicae, respectively, in Tarragona, Spain) were used as reference strains in the phylogenetic analysis.

Mycelial compatibility grouping isolates of $\boldsymbol{R}$. necatrix. To confirm results obtained in the ISSR analysis, a mycelial compatibility test was carried out among selected isolates (Armengol et al. 2010; Pérez-Jiménez et al. 2002). In all, 16 isolates (6 from FVG and 10 from TAA) were chosen: four pairs of isolates with the same pattern ( $100 \%$ similarity) and others with a lower percentage of similarity, ranging between 78.6 and $86.9 \%$. These isolates of $R$. necatrix were transferred to PDA and kept at $24^{\circ} \mathrm{C}$ in the dark for 7 days. Mycelial incompatibility among isolates was carried out by pairing of the cultures, as described by Pérez-Jiménez et al. (2002) and Armengol et al. (2010). Plates were incubated at $24^{\circ} \mathrm{C}$ in the dark and were checked every 15 days to evaluate the degree of barrage development within the zone of mycelial interaction.

In another repeated experiment, all isolates were transferred to PDA in 90-mm petri dishes and maintained as described above. Three petri dishes per isolate were prepared. The growth of the colonies (diameter) was measured after $24,48,72,96$, and $120 \mathrm{~h}$ and in vitro growth rate (millimeters per day) was calculated. Morphological characteristics of colonies were also recorded and compared with the results of ISSR analysis.

Apple infection assays. The trials were carried out on a study system based on potted apple seedlings, a method which accelerates symptom expression. The inoculum of $R$. necatrix for all experiments on apple seedlings was prepared as described by Ruano-Rosa and López Herrera (2009), with modifications. Briefly, $200 \mathrm{~g}$ of oat (Avena sativa) seed was soaked in $55 \mathrm{ml}$ of distilled water in a flask. The flask containing sterile seed was autoclaved twice on two consecutive days and then inoculated with 10 pieces ( 5 by $5 \mathrm{~mm}$ each) of a 7-day-old culture of an $R$. necatrix isolate. The flask was incubated for 15 days at $24^{\circ} \mathrm{C}$ in the dark, until $R$. necatrix grew uniformly, completely covering the oat seed, and then immediately used in the experiments. The test was also used to verify pathogenicity of the $R$. necatrix isolates.

Based on in vitro growth rates, inoculum was prepared from two groups of isolates (fast $=>10 \mathrm{~mm} /$ day and slow $=<6 \mathrm{~mm} /$ day). Three fast-growing strains (T16, T20, and T21) and three slow-growing strains (T7, F7, and T17) were tested on apple seedlings to evaluate pathogenicity and aggressiveness. Two repeated experiments were carried out under controlled greenhouse conditions, using apple seedlings obtained from seed of 'Golden Delicious' grown for 10 to 12 weeks in a seedbed. Soil water content was determined 
gravimetrically (oven dried at $105^{\circ} \mathrm{C}$ for $16 \mathrm{~h}$ ) to fill the pots with a quantity corresponding to $1 \mathrm{~kg}$ of dry soil. Seedling roots were washed with tap water to remove germination medium followed by transplanting to 1.3-liter plastic pots containing sandy-loam soil (2.5\% organic matter [pH 7.8], $66 \%$ sand, $30 \%$ silt, and $4 \%$ clay). Pots were irrigated and soil moisture was maintained at field capacity $(19 \pm 2 \%)$. The soil had been previously amended with colonized oat $(0.75 \mathrm{~g} / \mathrm{kg}$ of dried soil) and dried apple wood fragments obtained from shoots (approximately 5 by $5 \mathrm{~mm}, 66.7 \%$ organic matter content, amended at $15 \mathrm{~g} / \mathrm{kg}$ of dried soil). Each $R$. necatrix strain cited above was evaluated on three replicates of five plants per replicate. A negative control was represented by three replicates of five noninoculated plants. Disease severity was recorded for each plant every 7 to 10 days over a period of 3 months based on a 1-to-5 scale, as described by Ruano-Rosa and López Herrera (2009). Incidence of the disease (percentage of dead plants, score 5) was assessed and the area under the disease progress curve (AUDPC) (Campbell and Madden 1990) for each replicate and treatment was calculated. The procedure for producing apple seedlings, the number of plants for each treatment, and the recording-scoring procedure together with disease assessment and AUDPC calculation were the same in all of the following experiments.

Identification of soil conditions promoting $R$. necatrix growth and infections. The inoculum of $R$. necatrix and apple seedlings were prepared as mentioned above. The isolate T3 of $R$. necatrix was used in the following experiments. The influence of (i) temperature (25 and $16^{\circ} \mathrm{C}$ ), (ii) soil water content at field capacity (soil moisture $19 \pm$ $2 \%$ ) and saturation $(29 \pm 2 \%$ ), and (iii) amendments (mineral fertilizer with no organic matter, organic fertilizer, or wood fragments) was evaluated. When no organic matter was added, fertilization was given by three applications of a mineral fertilizer (N, P, and $\mathrm{K}$ at 4.2, 2.1, and $4.2 \mathrm{mg} / \mathrm{kg}$ of dried soil, respectively; KB-Scotts, Marysville, $\mathrm{OH}$ ) once a week for the first 3 weeks of the trial. An organic fertilizer $(41.3 \%$ organic matter content, $\mathrm{N}=2 \%, \mathrm{C} / \mathrm{N}=12 \%$, applied at $180 \mathrm{~g} / \mathrm{kg}$ of dried soil; Ortobon, Vicenza, Italy), apple wood fragments (as above), and $R$. necatrix inoculum were mixed into the soil just prior to filling of the pots and transplanting the seedlings.

Quantification of $\boldsymbol{R}$. necatrix DNA in soil. Soil samples were collected from six inoculated pots for each treatment (two per replicate) using a core tool $(1 \mathrm{~cm}$ in diameter at a depth of $6 \mathrm{~cm})$. In each pot, three samples were made near the roots, at a distance of $1 \mathrm{~cm}$ from the crown, and three more distal in the bulk soil of the pot; then, all six samples were bulked for analysis. Each soil sample was lyophilized and subsequently homogenized (Mixer Mill MM 200; Retsch $\mathrm{GmbH}$ ). Total DNA was obtained from $0.5 \mathrm{~g}$ of lyophilized soil with the FastDNA SPIN Kit for Soil (MP Biomedicals, Santa Ana, CA), according to the manufacturer's instructions. The amount of DNA was measured using a NanoDrop 8000 spectrophotometer (ThermoFisher Scientific), and all samples were diluted to a final concentration of $2 \mathrm{ng} / \mu \mathrm{l}$.

Real-time PCR was performed in a LightCycler 480 System (Roche Applied Science, Basel, Switzerland) using the KAPA SYBR

Table 1. Orchards with Rosellinia necatrix-infected apple tree plants sampled in the study

\begin{tabular}{|c|c|c|c|c|c|c|c|c|c|c|}
\hline $\begin{array}{l}\text { Orchard } \\
\text { code }\end{array}$ & Coordinates & $\begin{array}{l}\text { Isolate } \\
\text { code }\end{array}$ & Patch $^{y}$ & $\begin{array}{l}\text { Species, } \\
\text { cultivar, } \\
\text { rootstock }\end{array}$ & Nursery $^{z}$ & $\begin{array}{l}\text { Planting } \\
\text { year }\end{array}$ & $\begin{array}{l}\text { Previous } \\
\text { crops }\end{array}$ & $\begin{array}{l}\text { Surrounding } \\
\text { crops }\end{array}$ & $\begin{array}{l}\text { Distribution } \\
\text { of } \\
\text { symptomatic } \\
\text { plants }\end{array}$ & $\begin{array}{c}\text { Soil } \\
\text { texture }\end{array}$ \\
\hline \multirow[t]{2}{*}{ TAA1 } & $\begin{array}{l}46^{\circ} 09^{\prime} 46.5^{\prime \prime} \mathrm{N} \\
11^{\circ} 04^{\prime} 38.0^{\prime \prime} \mathrm{E}\end{array}$ & $\mathrm{T} 3$ & $\mathrm{a}$ & Apple, Fuji, M9 & 1 & 2002 & $\begin{array}{l}\text { Apple, old } \\
\text { plants }\end{array}$ & $\begin{array}{l}\text { Apple, } \\
\text { meadow, } \\
\text { forest }\end{array}$ & Patch & Sandy loam \\
\hline & $\ldots$ & $\mathrm{T} 22$ & $\mathrm{a}$ & Apple, Fuji, M9 & 1 & 2002 & $\begin{array}{l}\text { Apple, old } \\
\text { plants }\end{array}$ & $\begin{array}{l}\text { Apple, } \\
\text { meadow, } \\
\text { forest }\end{array}$ & Patch & Sandy loam \\
\hline \multirow[t]{6}{*}{ TAA2 } & $\begin{array}{l}46^{\circ} 01^{\prime} 46.9^{\prime \prime} \mathrm{N} \\
10^{\circ} 57^{\prime} 32.3^{\prime \prime} \mathrm{E}\end{array}$ & $\mathrm{T} 1$ & $\mathrm{~b}$ & $\begin{array}{l}\text { Apple, Dalinette, } \\
\text { M9 }\end{array}$ & 2 & 2010 & Pear, apple & $\begin{array}{l}\text { Apple, } \\
\text { grapevine }\end{array}$ & Patch & Loam \\
\hline & $\ldots$ & $\mathrm{T} 2$ & $\mathrm{~b}$ & Apple, Gala, M9 & 3 & 2010 & Pear, apple & $\begin{array}{l}\text { Apple, } \\
\text { grapevine }\end{array}$ & Patch & Loam \\
\hline & $\ldots$ & T9 & $\mathrm{a}$ & $\begin{array}{l}\text { Apple, Crimson } \\
\text { Crisp, M9 }\end{array}$ & 4 & 2010 & Pear, apple & $\begin{array}{l}\text { Apple, } \\
\text { grapevine }\end{array}$ & Patch & Loam \\
\hline & $\ldots$ & T10 & $\mathrm{a}$ & $\begin{array}{l}\text { Apple, Crimson } \\
\text { Crisp, M9 }\end{array}$ & 4 & 2010 & Pear, apple & $\begin{array}{l}\text { Apple, } \\
\text { grapevine }\end{array}$ & Patch & Loam \\
\hline & $\ldots$ & $\mathrm{T} 11$ & $\mathrm{a}$ & Apple, Gala, M9 & 3 & 2010 & Pear, apple & $\begin{array}{l}\text { Apple, } \\
\text { grapevine }\end{array}$ & Patch & Loam \\
\hline & $\cdots$ & $\mathrm{T} 12$ & a & Apple, Gala, M9 & 3 & 2010 & Pear, apple & $\begin{array}{l}\text { Apple, } \\
\text { grapevine }\end{array}$ & Patch & Loam \\
\hline TAA3 & $\begin{array}{l}45^{\circ} 58^{\prime} 08.4^{\prime \prime} \mathrm{N} \\
10^{\circ} 55^{\prime} 09.5^{\prime \prime} \mathrm{E}\end{array}$ & T16 & $\mathrm{a}$ & Plum & $\begin{array}{l}\text { Local } \\
\text { origin }\end{array}$ & $>10$ years & Plum & $\begin{array}{l}\text { Grapevine, } \\
\text { plum }\end{array}$ & Patch & $\begin{array}{l}\text { Sandy loam, } \\
\text { gravel }\end{array}$ \\
\hline TAA4 & $\begin{array}{l}45^{\circ} 53^{\prime} 38.2^{\prime \prime} \mathrm{N} \\
10^{\circ} 51^{\prime} 32.3^{\prime \prime} \mathrm{E}\end{array}$ & T15 & a & Pear & $\begin{array}{l}\text { Local } \\
\text { origin }\end{array}$ & 2012 & Apple, pear & $\begin{array}{l}\text { Grapevine, } \\
\text { ornamentals }\end{array}$ & Patch & Silt loam \\
\hline \multirow[t]{2}{*}{ TAA5 } & $\begin{array}{l}46^{\circ} 19^{\prime} 15.8^{\prime \prime} \mathrm{N} \\
11^{\circ} 01^{\prime} 03.8^{\prime \prime} \mathrm{E}\end{array}$ & $\mathrm{T} 20$ & nd & $\begin{array}{l}\text { Apple, Renetta } \\
\text { Canada, M9 }\end{array}$ & 5 & 2008 & $\begin{array}{l}\text { Grapevine, } \\
\text { apple }\end{array}$ & Apple, apricot & Single plants & Loam, gravel \\
\hline & $\ldots$ & $\mathrm{T} 21$ & nd & $\begin{array}{l}\text { Apple, Red } \\
\text { Deliciuos, M9 }\end{array}$ & 5 & 2008 & $\begin{array}{l}\text { Grapevine, } \\
\text { apple }\end{array}$ & Apple, apricot & Single plants & Loam, gravel \\
\hline \multirow[t]{2}{*}{ TAA6 } & $\begin{array}{l}46^{\circ} 17^{\prime} 37.1^{\prime \prime} \mathrm{N} \\
11^{\circ} 06^{\prime} 05.8^{\prime \prime} \mathrm{E}\end{array}$ & $\mathrm{T} 4$ & a & Apple, Golden, M9 & 6 & 2002 & $\begin{array}{l}\text { Forest, } \\
\text { apple }\end{array}$ & Apple, forest & Patch & Loam, gravel \\
\hline & $\ldots$ & T14 & $\mathrm{b}$ & Apple, Golden, M9 & 6 & 2002 & $\begin{array}{l}\text { Forest, } \\
\text { apple }\end{array}$ & Apple, forest & Patch & Loam, gravel \\
\hline \multirow[t]{2}{*}{ TAA7 } & $\begin{array}{l}46^{\circ} 22^{\prime} 47.3^{\prime \prime} \mathrm{N} \\
11^{\circ} 03^{\prime} 10.7^{\prime \prime} \mathrm{E}\end{array}$ & T17 & nd & Apple, Golden, M9 & 7 & 2009 & $\begin{array}{l}\text { Grapevine, } \\
\text { apple }\end{array}$ & $\begin{array}{l}\text { Apple, } \\
\text { grapevine }\end{array}$ & Patch & $\begin{array}{l}\text { Sandy loam, } \\
\text { gravel }\end{array}$ \\
\hline & $\ldots$ & T18 & nd & Apple, Golden, M9 & 7 & 2009 & $\begin{array}{l}\text { Grapevine, } \\
\text { apple }\end{array}$ & $\begin{array}{l}\text { Apple, } \\
\text { grapevine }\end{array}$ & Patch & $\begin{array}{l}\text { Sandy loam, } \\
\text { gravel }\end{array}$ \\
\hline TAA8 & $\begin{array}{l}46^{\circ} 22^{\prime} 47.4^{\prime \prime} \mathrm{N} \\
11^{\circ} 03^{\prime} 11.9^{\prime \prime} \mathrm{E}\end{array}$ & T6 & nd & Apple, Golden, M9 & 8 & 2010 & $\begin{array}{l}\text { Grapevine, } \\
\text { apple }\end{array}$ & $\begin{array}{l}\text { Apple, } \\
\text { grapevine }\end{array}$ & Patch & $\begin{array}{l}\text { Sandy loam, } \\
\text { gravel }\end{array}$ \\
\hline
\end{tabular}

\footnotetext{
y Different letters within the same orchard mean different patches of diseased plants; nd indicates patches not clearly determined.
}

z Different numbers indicate different nurseries. 
FAST qPCR Kit (Master Mix [2×] optimized for LightCycler 480; Kapa Biosystems, Wilmington, MA). Each reaction consisted of $1 \mu l(2 \mathrm{ng})$ of DNA extract, $10 \mu 1$ of KAPA SYBR FAST qPCR Master Mix (2×), and $0.2 \mu \mathrm{M}$ specific primer set R10-R7 (Schena et al. 2002 ) in a final volume of $20 \mu \mathrm{l}$. The amplification protocol was an initial denaturation cycle at $95^{\circ} \mathrm{C}$ for $3 \mathrm{~min}$, followed by 40 cycles of $3 \mathrm{~s}$ at $95^{\circ} \mathrm{C}$ and $30 \mathrm{~s}$ at $61^{\circ} \mathrm{C}$ of annealing and extension, with fluorescence data collected after each annealing and extension step. A melting curve profile was generated by increasing the temperature from 55 to $95^{\circ} \mathrm{C}$ in increments of $2.2^{\circ} \mathrm{C} / \mathrm{s}$ to visualize specific amplicons, nonspecific amplification products, and potential primer dimers. Fluorescence data were analyzed using second-derivative maximum analysis (LightCycler Software, version 1.5). Cycle threshold $(\mathrm{Ct})$ number, amplification curves, and calibration curves were generated from LightCycler data analysis. The calibration curve was generated by adding different amounts of lyophilized $R$. necatrix mycelium to sterilized soil, and checked for the absence of $R$. necatrix DNA by conventional PCR with specific primers (R7 and R10). Briefly, powdered lyophilized mycelium was suspended in sterile water at a concentration of $100 \mathrm{mg} / \mathrm{ml}$ overnight at $4^{\circ} \mathrm{C}$, from which dilutions were mixed to $250 \mathrm{mg}$ to obtain concentrations of mycelium at 10,2, 0.4, 0.08, and $0.016 \mathrm{mg} / \mathrm{g}$ of soil. The calibration curve was generated using the second-derivative maximum analysis (LightCycler Software, version 1.5), plotting the $\mathrm{Ct}$ values (cycle number at which the fluorescence emission exceeds a fixed threshold established in the exponential phase of the amplification curve) obtained for each concentration (consisting of two different replicates) against the logarithm of the corresponding amount of mycelium. Mycelium at $2 \mathrm{mg} / \mathrm{g}$ of soil was included in each 96-plate sample quantification as reference standard. Absolute quantification of $R$. necatrix mycelium in soil samples was determined by interpolation of the $\mathrm{Ct}$ values in the standard curve and expressed as milligrams of mycelium per gram of soil.

In vitro biocontrol experiments. The biocontrol efficacy of $T$. atroviride $\mathrm{SC} 1$ against $R$. necatrix (T3 isolate) was first checked in dual cultures. Petri dishes (90 $\mathrm{mm}$ in diameter) containing $20 \mathrm{ml}$ of PDA were coinoculated with the pathogen and the biocontrol agent (three replicates per treatment). Briefly, a 5-mm-diameter disc of a 7-day-old culture of $R$. necatrix was placed at $20 \mathrm{~mm}$ from the edge of each petri dish. After 3 days of incubation at $25^{\circ} \mathrm{C}$ in darkness, a 5-mm-diameter disc of a 3-day-old culture of $T$. atroviride $\mathrm{SC} 1$ was inoculated $50 \mathrm{~mm}$ from the $R$. necatrix disc. Radial growth of $R$. necatrix was measured daily after incubation at $25^{\circ} \mathrm{C}$ for 5 days. Percent radial growth inhibition was calculated based on growth of $R$. necatrix cultures without $T$. atroviride.

Biocontrol experiments on apple seedlings. $R$. necatrix inoculum was prepared as described above. A commercial formulation of $T$. atroviride SC1 $\left(1 \times 10^{10} \mathrm{CFU} / \mathrm{g}\right.$; Vintec, Belchim Crop Protection, Belgium) was used at a concentration of approximately $1 \times 10^{7}$ $\mathrm{CFU} / \mathrm{g}$ of dried soil. Experiments were performed under controlled greenhouse conditions (temperature of $25 \pm 2{ }^{\circ} \mathrm{C}$, soil water content around field capacity, and relative humidity of $70 \pm 5 \%$ ). Plant material, soil, and pots were the same as described above.

Table 1. (continued from preceding page)

\begin{tabular}{|c|c|c|c|c|c|c|c|c|c|c|}
\hline $\begin{array}{l}\text { Orchard } \\
\text { code }\end{array}$ & Coordinates & $\begin{array}{l}\text { Isolate } \\
\text { code }\end{array}$ & Patch $^{y}$ & $\begin{array}{l}\text { Species, } \\
\text { cultivar, } \\
\text { rootstock }\end{array}$ & Nursery $^{\mathbf{z}}$ & $\begin{array}{l}\text { Planting } \\
\text { year }\end{array}$ & $\begin{array}{l}\text { Previous } \\
\text { crops }\end{array}$ & $\begin{array}{l}\text { Surrounding } \\
\text { crops }\end{array}$ & $\begin{array}{c}\text { Distribution } \\
\text { of } \\
\text { symptomatic } \\
\text { plants }\end{array}$ & $\begin{array}{l}\text { Soil } \\
\text { texture }\end{array}$ \\
\hline & $\cdots$ & $\mathrm{T} 7$ & a & Apple, Golden, M9 & 8 & 2010 & $\begin{array}{l}\text { Grapevine, } \\
\text { apple }\end{array}$ & $\begin{array}{l}\text { Apple, } \\
\text { grapevine }\end{array}$ & Patch & $\begin{array}{l}\text { Sandy loam, } \\
\text { gravel }\end{array}$ \\
\hline & $\cdots$ & $\mathrm{T} 8$ & nd & Apple, Golden, M9 & 8 & 2010 & $\begin{array}{l}\text { Grapevine, } \\
\text { apple }\end{array}$ & $\begin{array}{l}\text { Apple, } \\
\text { grapevine }\end{array}$ & Patch & $\begin{array}{l}\text { Sandy loam, } \\
\text { gravel }\end{array}$ \\
\hline & $\cdots$ & $\mathrm{T} 24$ & $\mathrm{~b}$ & Apple, Golden, M9 & 8 & 2010 & $\begin{array}{l}\text { Grapevine, } \\
\text { apple }\end{array}$ & $\begin{array}{l}\text { Apple, } \\
\text { grapevine }\end{array}$ & Patch & $\begin{array}{l}\text { Sandy loam, } \\
\text { gravel }\end{array}$ \\
\hline \multirow[t]{2}{*}{ TAA9 } & $\begin{array}{l}46^{\circ} 22^{\prime} 51.8^{\prime \prime} \mathrm{N} \\
11^{\circ} 03^{\prime} 06.3^{\prime \prime} \mathrm{E}\end{array}$ & T5 & $\mathrm{a}$ & $\begin{array}{l}\text { Apple, Golden, } \\
\text { M26 }\end{array}$ & 9 & 2010 & Apple & Apple & Patch & $\begin{array}{l}\text { Sandy loam, } \\
\text { gravel }\end{array}$ \\
\hline & $\ldots$ & $\mathrm{T} 23$ & $\mathrm{~b}$ & Apple, Golden, M9 & 9 & 2010 & Apple & Apple & Patch & $\begin{array}{l}\text { Sandy loam, } \\
\text { gravel }\end{array}$ \\
\hline TAA10 & $\begin{array}{l}46^{\circ} 22^{\prime} 50.9^{\prime \prime} \mathrm{N} \\
11^{\circ} 03^{\prime} 07.7^{\prime \prime} \mathrm{E}\end{array}$ & T19 & $\mathrm{a}$ & Apple, Golden, M9 & 9 & 2009 & Apple & Apple & Single plant & $\begin{array}{l}\text { Sandy loam, } \\
\text { gravel }\end{array}$ \\
\hline TAA11 & $\begin{array}{l}46^{\circ} 24^{\prime} 12.04^{\prime \prime} \mathrm{N} \\
11^{\circ} 4^{\prime} 53.31^{\prime \prime} \mathrm{E}\end{array}$ & $\mathrm{T} 25$ & a & Apple, Golden, M9 & 5 & 2009 & $\begin{array}{l}\text { Grapevine, } \\
\text { apple }\end{array}$ & Apple, fallow & Patch & Loam, gravel \\
\hline \multirow[t]{4}{*}{ FVG1 } & $\begin{array}{l}45^{\circ} 56^{\prime} 55.61^{\prime \prime} \mathrm{N} \\
13^{\circ} 9^{\prime} 57.82^{\prime \prime} \mathrm{E}\end{array}$ & F5 & a & $\begin{array}{l}\text { Apple, Golden } \\
\text { Rush, M9 }\end{array}$ & 10 & 2009 & $\begin{array}{l}\text { Vegetables, } \\
\text { apple }\end{array}$ & Apple & Single plants & Loam, gravel \\
\hline & $\ldots$ & F6 & $\mathrm{b}$ & $\begin{array}{l}\text { Apple, Golden } \\
\text { Rush, M9 }\end{array}$ & 10 & 2009 & $\begin{array}{l}\text { Vegetables, } \\
\text { apple }\end{array}$ & Apple & Single plants & Loam, gravel \\
\hline & $\cdots$ & F7 & nd & $\begin{array}{l}\text { Apple, Golden } \\
\text { Rush, M9 }\end{array}$ & 10 & 2009 & $\begin{array}{l}\text { Vegetables, } \\
\text { apple }\end{array}$ & Apple & Single plants & Loam, gravel \\
\hline & $\cdots$ & F8 & nd & $\begin{array}{l}\text { Apple, Golden } \\
\text { Rush, M9 }\end{array}$ & 10 & 2009 & $\begin{array}{l}\text { Vegetables, } \\
\text { apple }\end{array}$ & Apple & Single plants & Loam, gravel \\
\hline FVG2 & $\begin{array}{l}45^{\circ} 59^{\prime} 22.06^{\prime \prime} \mathrm{N} \\
13^{\circ} 0^{\prime} 16.93^{\prime \prime} \mathrm{E}\end{array}$ & $\mathrm{F} 4$ & $\mathrm{a}$ & Apple, Gala, M106 & 11 & 2003 & Apple & Apple & Patch & Loam, gravel \\
\hline FVG3 & $\begin{array}{l}45^{\circ} 55^{\prime} 19.22^{\prime \prime} \mathrm{N} \\
13^{\circ} 13^{\prime} 16.93^{\prime \prime} \mathrm{E}\end{array}$ & $\mathrm{F} 2$ & $\mathrm{a}$ & $\begin{array}{l}\text { Apple, Golden, } \\
\text { M26 }\end{array}$ & 12 & $>10$ years & Apple & Apple & Patch & Loam, gravel \\
\hline FVG4 & $\begin{array}{l}46^{\circ} 5^{\prime} 26.60^{\prime \prime} \mathrm{N} \\
12^{\circ} 49^{\prime} 27.90^{\prime \prime} \mathrm{E}\end{array}$ & F1 & $\mathrm{a}$ & Apple, Golden, M9 & 13 & $>10$ years & Apple & $\begin{array}{l}\text { Apple, } \\
\text { grapevine }\end{array}$ & Patch & $\begin{array}{l}\text { Sandy-loam, } \\
\text { gravel }\end{array}$ \\
\hline \multirow[t]{2}{*}{ FVG5 } & $\begin{array}{l}46^{\circ} 6^{\prime} 24.89^{\prime \prime} \mathrm{N} \\
12^{\circ} 54^{\prime} 44.92^{\prime \prime} \mathrm{E}\end{array}$ & F10 & a & Apple, Golden, M9 & 14 & $>10$ years & Apple & $\begin{array}{l}\text { Apple, } \\
\text { grapevine, } \\
\text { arable crops }\end{array}$ & Widespread & $\begin{array}{l}\text { Sandy-loam, } \\
\text { gravel }\end{array}$ \\
\hline & $\cdots$ & F11 & a & Apple, Golden, M9 & 14 & $>10$ years & Apple & $\begin{array}{l}\text { Apple, } \\
\text { grapevine, } \\
\text { arable crops }\end{array}$ & Widespread & $\begin{array}{l}\text { Sandy-loam, } \\
\text { gravel }\end{array}$ \\
\hline FVG6 & $\begin{array}{l}45^{\circ} 59^{\prime} 59.46^{\prime \prime} \mathrm{N} \\
12^{\circ} 53^{\prime} 14.58^{\prime \prime} \mathrm{E}\end{array}$ & F9 & a & Apple, Golden, M9 & 15 & 2009 & Apple & $\begin{array}{l}\text { Apple, arable } \\
\text { crops }\end{array}$ & Patch & $\begin{array}{l}\text { Sandy-loam, } \\
\text { gravel }\end{array}$ \\
\hline FVG7 & $\begin{array}{l}46^{\circ} 8^{\prime} 41.08^{\prime \prime} \mathrm{N} \\
12^{\circ} 50^{\prime} 25.49^{\prime \prime} \mathrm{E}\end{array}$ & F3 & $\mathrm{a}$ & $\begin{array}{l}\text { Apple, Cripps Pink, } \\
\text { M9 }\end{array}$ & 12 & 2006 & $\begin{array}{l}\text { Meadow, } \\
\text { apple }\end{array}$ & Apple & Patch & $\begin{array}{l}\text { Sandy-loam, } \\
\text { gravel }\end{array}$ \\
\hline
\end{tabular}


Applications of $T$. atroviride SC1 (1 g/pot) 1 week before and 1 week after the inoculation of soil with $R$. necatrix $(0.75 \mathrm{~g}$ of colonized seed/pot) were compared. Because chitin may promote chitinase production by the biocontrol agent, the addition of milled shrimp shells to the soil ( $3 \mathrm{~g} / \mathrm{pot})$ was also tested in combination with $T$. atroviride SC1. Each treatment was applied on three replicates of five plants each. Positive controls were inoculated with $R$. necatrix only. Negative controls were treated only with $T$. atroviride $\mathrm{SC} 1$, milled shrimp shells, or left untreated. Apple seedlings were potted at the same time of SC1 application in treatments previously inoculated with the pathogen or together with $R$. necatrix in pots previously treated with SC1. T. atroviride SC1 was also applied contemporaneously to $R$. necatrix inoculum (colonized seed at $0.75 \mathrm{~g} / \mathrm{pot}$ ) to the soil 30 days before transplanting apple seedlings into the pots.

Quantification of $T$. atroviride SC1 and its DNA in the biocontrol experiments. The concentration of $T$. atroviride was assessed at the beginning and at the end of the experiments: 7 and 90 days after application, respectively. Samples of soil were taken from three different pots of each treatment, as described above, and $1 \mathrm{~g}$ of each soil sample was suspended in $10 \mathrm{ml}$ of sterile water, serially diluted, and plated $(1 \mathrm{ml})$ in petri dishes containing a semiselective medium (PDA supplemented with rose Bengal at $100 \mu \mathrm{g} / \mathrm{g}$, chloramphenicol at $50 \mu \mathrm{g} / \mathrm{g}$, and streptomycin at $100 \mu \mathrm{g} / \mathrm{g}$; Sigma Aldrich) and incubated at $25^{\circ} \mathrm{C}$. CFU were counted after 3 days of incubation. Soil humidity was calculated and the $\mathrm{CFU}$ values were given per gram of dry soil. T. atroviride SC1 DNA was quantified following the same protocols as described above for $R$. necatrix DNA, with the exception of the primers used, which were, in this case, specific for endochitinase gene ech42 of T. atroviride SC1 (Savazzini et al. 2008). A calibration curve was generated as described for $R$. necatrix quantification using, in this case, T. atroviride SC1 mycelium.

Statistical analysis. Data were subjected to analysis of variance (ANOVA) using the software Statistica 9.0 (Statsoft, Tulsa, OK). Factorial ANOVA was used to analyze the data regarding soil conditions promoting $R$. necatrix infections and its DNA quantification. One-way ANOVA was used in the other experiments. Because no significant difference between two repeated experiments was found, the data were pooled and analyzed together. Means between treatments in each experiment were separated using the Tukey's honest significant difference test with $\alpha=5 \%$.

\section{Results}

Sampling, isolation, and identification of $R$. necatrix from apple tree roots. Nine apple tree orchards in TAA and seven in FVG were found to be infected with $R$. necatrix. One plum and one pear infected plots were also found in TAA (Table 1). In all, 35 isolates of putative $R$. necatrix, 24 from TAA and 11 from FVG, were collected from these orchards. Based on morphological characteristics and PCR with the specific primers R2 and R8, all 35 isolates were classified as $R$. necatrix.

The map of the infected areas and orchards where samples were taken is shown in Supplementary Figure S1. Within the orchards, M9 was the prevalent rootstock with white root rot with M26 and M106 also infected. Origins of the trees varied, with only three pairs of orchards having trees from the same nursery. Both young (1 to 3 years) and old (more than 10 years) apple trees were diseased. Apple and grapevine were the main crops grown previously at these sites. Symptomatic trees were distributed mainly in patches of varying dimensions but occasionally single diseased trees were observed (Supplementary Fig. S2). The soil was always loose, sandy or sandy-loam, rich-gravel. The incidence of the disease ranged from a few plants ( $<1 \%$ symptomatic plants) to 20 to $30 \%$ in the worst orchards. The first symptoms were noticed by the growers either a few years ago or 20 to 30 years ago.

R. necatrix population analysis. Analysis of ISSR molecular markers showed the $R$. necatrix isolates to be genetically diverse. Isolates could be separated into two main clusters (cluster 1 and 2), defined by 82.3 and $82.5 \%$ similarity, respectively, and into two minor clusters (cluster 3 and 4), with 83.5 and $79.4 \%$ similarity, respectively (Fig. 1). Only the pair of isolates T3 and T22 and the isolate $\mathrm{T} 14$ were excluded from the main groups, showing similarity values of 78.6 and $79.1 \%$, respectively, with the two main clusters (Fig. 1).

FVG isolates (F1 and F5 to F11) mostly grouped into cluster 1, with $86 \%$ similarity, but F2, F3, and F4 isolates from the same region showed greater similarity with TAA isolates (Fig. 1). This indicates that geographical origin was not strongly correlated with isolate grouping. Orchard proximity also did not correlate to genetic distance among isolates. For example, orchards TAA7, TAA8, TAA9, and TAA10 were sampled from the same municipality (Table 1) but the isolates from these orchards were positioned on different branches of the final dendrogram (Fig. 1). Orchards made up of trees of the same cultivar but coming from different nurseries (i.e., TAA5, TAA6, TAA7, TAA8, and FVG1; Table 1) showed multiple patches of trees infected by genetically distinct isolates of $R$. necatrix (Table 1; Fig. 1). In addition, three pairs of orchards with trees originating from the same nursery (TAA9-TAA10, TAA5-TAA11, and FVG3-FVG7) had isolates of $R$. necatrix that were genetically different. Based on this evidence, we assume that root rot in apple orchards of this area did not originate from the nurseries.

The two reference strains from Spain, C1 and C2, were isolated from peach and olive trees, respectively; and, in this study, they were placed in cluster 2 , showing about $85 \%$ similarity (Fig. 1). Also, T15 and T16 were isolated from hosts other than apple (pear and plum, respectively) and, after molecular analysis, they were placed in clusters 3 and 1, respectively (Fig. 1). R. necatrix strains do not group according to host specificity. When two or more isolates exhibited $100 \%$ genetic similarity, they were considered to be the same strain. This usually occurred for those isolates sampled in the same patch of the same orchard, as shown by the isolates T1-T2, T3-T22, T9-T10-T11-T12, and F10-F11 (Fig. 1). When isolates were derived from the same orchard but from distinct patches of infection, they usually showed a similarity lower than $100 \%$. This is the case for the pairs of isolates T4-T14, T5-T23, F5-F6, and T7T24 and occurred also for the two groups of isolates T9-T10T11-T12 and T1-T2. Moreover, some pairs of isolates (F7-F8, T6-T8, T17-T18, and T20-T21), derived from the same orchard but from patches that could not be clearly determined (Fig. 1), showed perfect genetic profile matching. This could be explained on the basis that the agricultural practices performed during the realization of the orchard could play a significant role in the spreading of the disease in multiple infected zones, starting from a single preexisting infection source. For example, the orchards TAA8 (isolates T6-T8) and TAA7 (isolates T17-18) have a steep slope and the ground was moved to create terracing and roads; therefore, the patches could originate from a single infection source.

Mycelial compatibility grouping and morphology of isolates of $\boldsymbol{R}$. necatrix. Similarity values obtained with molecular analysis were confirmed by mycelial compatibility analysis among selected isolates. All four pairings (F10 and F11, T9 and T10, T10 and T11, and T20 and T21) between isolates showing 100\% similarity at ISSR analysis showed the typical mycelial compatibility reaction, with growing mycelia superimposing and creating a uniform surface (Supplementary Fig. S3). Mycelial incompatibility reactions, with the formation of the barrage in the interaction area of the colonies, were observed pairing isolates with similarity lower than $100 \%$.

The growth rate of $R$. necatrix isolates after $120 \mathrm{~h}$ on PDA at $24^{\circ} \mathrm{C}$ ranged from 4.5 to $15.7 \mathrm{~mm} /$ day, showing significant differences in colony diameter (ANOVA; $P<0.01, F=34.2$, df $=36$ ). In this experiment, mycelium of the isolates varied from white-cottony to white with black-crusted areas to gray to light brown. Isolates with $100 \%$ similarity at ISSR analysis showed the same morphological characteristics.

Pathogenicity and aggressiveness of $R$. necatrix isolates. $R$. necatrix fast-growing strains T16, T20, and T21 (growth rates of $14.8,15.6$, and $15.8 \mathrm{~mm} /$ day, respectively) and slow-growing strains $\mathrm{T} 7, \mathrm{~F} 7$, and T17 (growth rates of 4.4, 5.6, and $6 \mathrm{~mm} /$ day, respectively) were inoculated onto apple seedlings to evaluate the relationship between aggressiveness and growth rate. For the fast and slow 
groups, first symptoms appeared 25 to 28 days after inoculation. At 90 days after inoculation, the proportion of dead plants and the AUDPC values calculated for the two groups were statistically similar (ANOVA; $P=0.27, F=1.3, \mathrm{df}=1 ; 71.1 \pm 10.2$ and $57.7 \pm 12.2 \%$ mean \pm standard error [SE] for the slow- and fast-growing strains, respectively). Consequently, no causal relation between in vitro growth rate and aggressiveness on apple plantlets was found.

Soil conditions promoting infection by $R$. necatrix and quantification of its DNA in soil. The progress of the white root rot in apple seedlings subjected to different environmental conditions was monitored over a period of 90 days. For the temperature treatments at 25 and $16^{\circ} \mathrm{C}$, the first symptoms (wilted leaves) appeared 27 to 29 and 31 to 36 days after planting, respectively. Shortly thereafter, the typical white cottony mycelium of $R$. necatrix appeared on the soil surface near the seedling crown. Symptom severity increased with time, with the temperature treatment of $25^{\circ} \mathrm{C}$ and the near-field-capacity soil water content resulting in the highest AUDPC values (Fig. 2A). Lower temperatures and water saturation of the soil resulted in less disease. The combination of $16^{\circ} \mathrm{C}$ and water saturation gave the best results in terms of reducing plant mortality (Fig. 2A)

The effects of organic fertilizer, mineral fertilizer, and wood fragments on the development of fungus also were evaluated in the experiments. Only the organic fertilizer at $25^{\circ} \mathrm{C}$ and in the presence of soil water content at field capacity significantly promoted pathogen aggressiveness, compared with the other amendments applied under the same conditions (Fig. 2A; ANOVA; $P<0.01, F=11.7$, $\mathrm{df}=11)$.

Real-time PCR using SYBR Green and specific primers (R10 and $\mathrm{R} 7)$ resulted in positive detection of $R$. necatrix DNA from extracted soil samples. Quantified amounts of pathogen DNA correlated positively with AUDPC values $\left(y=0.002 x+0.3963 ; R^{2}=0.88\right)$, highlighting the fact that the treatments with higher pathogen levels resulted in greater disease (Fig. 2B; ANOVA; $P<0.01, F=4.8$, $\mathrm{df}=11$ ). Only the interaction between the factors temperature and water are significant both for the AUDPC of dead plants and for Rosellinia mycelium (factorial ANOVA; AUDPC of percent dead plants: $P<0.01, F=19.3, \mathrm{df}=1 ; R$. necatrix mycelium [milligrams per gram of soil]: $P<0.01, F=7.09$, df $=1$ ).

In vitro biocontrol experiments. $T$. atroviride $\mathrm{SC} 1$ antagonized $R$. necatrix in dual culture experiments, confirming its potential use as a biocontrol agent. In control plates, the pathogen mycelium colonized the medium after 5 days of incubation at $25^{\circ} \mathrm{C}$ (about $11 \mathrm{~mm} /$ day) whereas, in dual cultures with $T$. atroviride, $R$ necatrix growth slowed after 2 days, and was overrun by the antagonist in the following 3 days of measurement. The percentage of radial growth inhibition reached 54\% 7 days after $R$. necatrix inoculation.

In planta biocontrol experiments and quantification of $T$. atroviride SC1 and $\boldsymbol{R}$. necatrix in soil. At 1 week after the inoculation, the average concentration of $T$. atroviride was about $5 \times 10^{6} \mathrm{CFU} / \mathrm{g}$ of soil while, at the end of the experiments ( 90 days after inoculation), it decreased to $5 \times 10^{4} \mathrm{CFU} / \mathrm{g}$ of soil. CFU of Trichoderma spp. before the $T$. atroviride $\mathrm{SC} 1$ application were $1.33 \times 10^{3}$ $\mathrm{CFU} / \mathrm{g}$ of soil.

The first symptoms appeared 25 to 27 days after planting. When $T$. atroviride SC1 was applied 1 week after pathogen inoculation, the disease incidence was not statistically different from that recorded on the control plants, inoculated only with the pathogen (Fig. 3A). When the inoculation of $T$. atroviride $\mathrm{SC} 1$ was performed 1 week

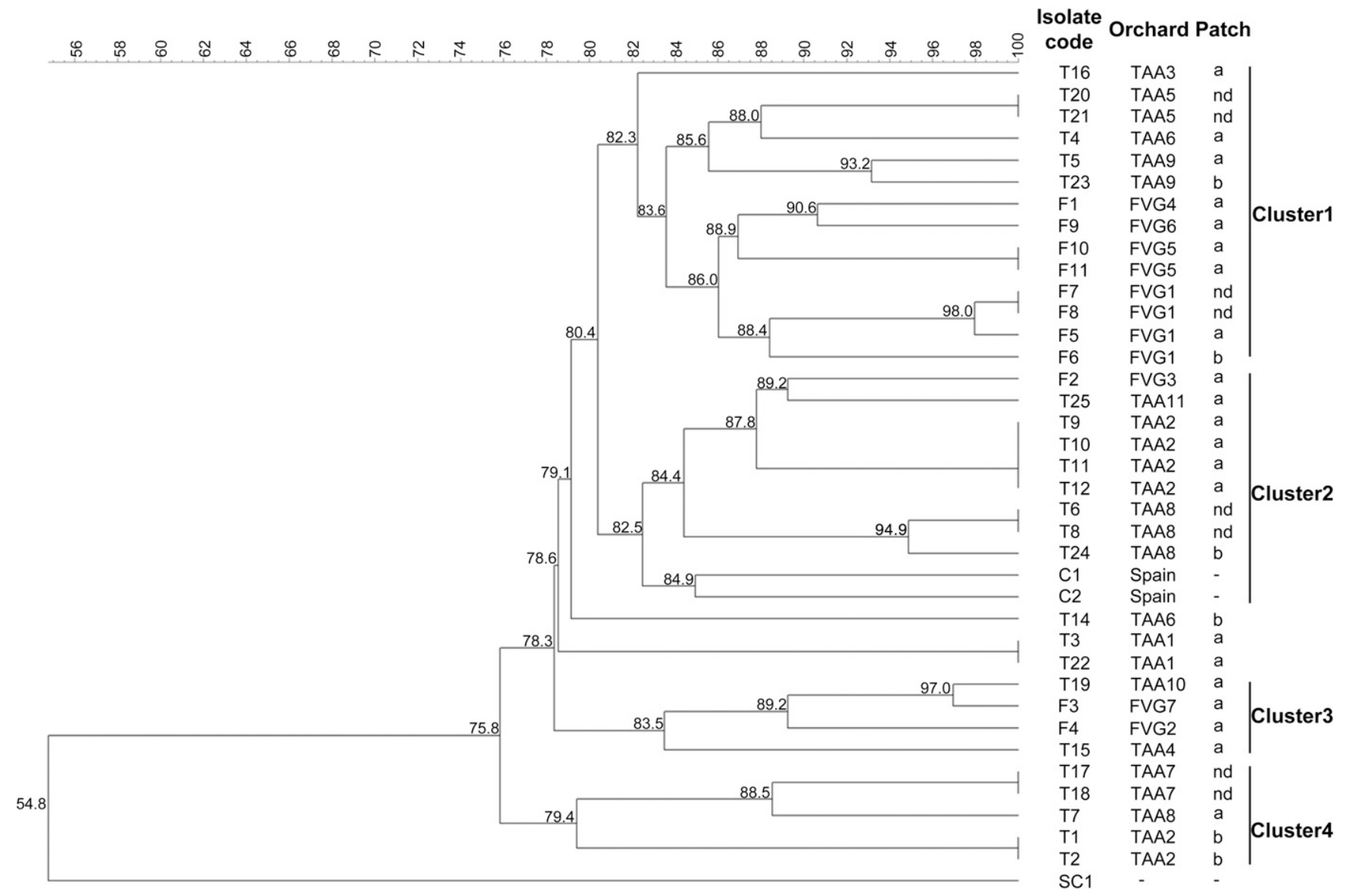

Fig. 1. Dendrogram showing genetic diversity among 37 Rosellinia necatrix isolates from infected apple trees and other hosts. Isolate, orchard, and patch codes are reported. The main four clusters are also shown. The dendrogram was built by the unweighted pair-group method with arithmetic mean and was calculated by averaging similarity values resulting from the single intersimple sequence repeat markers. In the Patch column, different letters for the same orchard mean different patches of diseased plants and "nd" indicates patches not clearly determined. Isolate code SC1 (Trichoderma atroviride strain SC1) represents a different genus used as reference. 
before adding the pathogen, the percentage of plant mortality significantly decreased, as shown by the lower AUDPC values (Fig. 3A; ANOVA; $P<0.01, F=10.1, \mathrm{df}=5$ ). Similar results were obtained when inoculating together the pathogen and T. atroviride $\mathrm{SC} 1$ and waiting 30 days before transplanting apple plants. Also, in this case, the AUDPC value significantly differed from the positive controls ( $R$. necatrix) and from treatments where $R$. necatrix was added before the $T$. atroviride $\mathrm{SC} 1$ strain. The addition to soil of milled shrimp shells as a chitin source did not induce a significant increment in biocontrol activity of Trichoderma spp. When milled shrimp shells were added together with the pathogen, AUDPC values were similar to those of the positive control ( $R$. necatrix) whereas, when added at the same time with $T$. atroviride $\mathrm{SC} 1$, disease incidence was reduced but no statistical differences were observed (Fig. 3A).

Real-time PCR was applied for the quantification of mycelium of both soilborne fungi. In soil samples collected at the beginning of the experiment, the $T$. atroviride $\mathrm{SC} 1$ mycelium amount was estimated at $15 \pm 0.5 \mathrm{mg} / \mathrm{g}$ (mean $\pm \mathrm{SE}$ ) of lyophilized soil whereas, at the end of the experiments, it could be detected at an average of $1.3 \pm 0.2 \mathrm{mg} / \mathrm{g}$ of soil.

Soil samples of treatments where the pathogen was inoculated before $T$. atroviride $\mathrm{SC} 1$ and the positive control were collected from replicates in which plants were all dead. In such samples, the quantities of $R$. necatrix mycelium ranged from 10.6 to $18.2 \mathrm{mg} / \mathrm{g}$ of soil, 90 days after inoculation (Fig. 3B). From treatments with $T$. atroviride SC1 applied before the pathogen, soil was sampled from both dead and healthy plants. $R$. necatrix mycelium reached about $6 \mathrm{mg} / \mathrm{g}$ of soil in dead replicates, whereas it was almost undetectable (lower than $0.1 \mathrm{mg} / \mathrm{g}$ ) in replicates where plants were healthy (Fig. 3B; ANOVA; $P<$ $0.01, F=8.3$, df $=4$ ). In the case of samples taken from treatments where the two fungi were inoculated together, similar results were obtained. The pathogen could not be detected in soils collected from healthy plants. Quantitative PCR data showed a high correlation with AUDPC values $(y=0.0139 x-7.0494$; $R^{2}=0.96$ ).

A

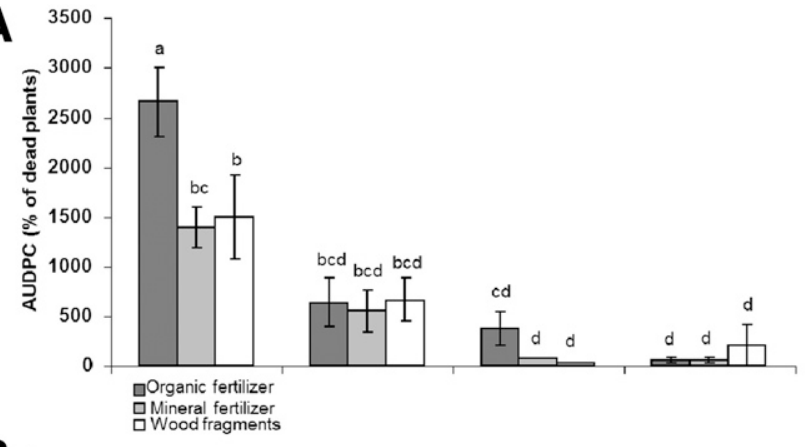

B

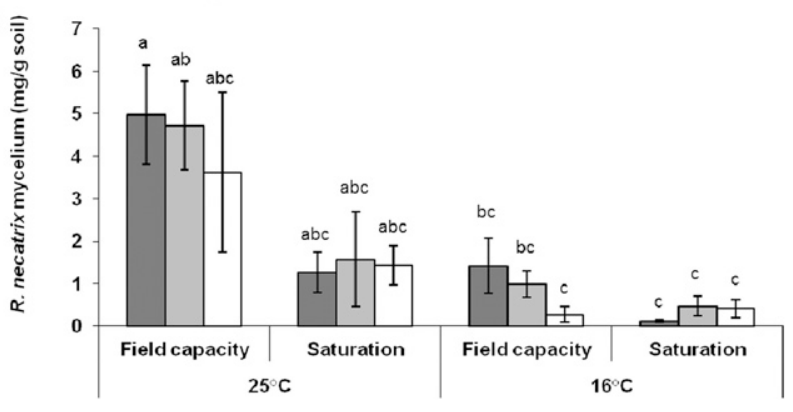

Fig. 2. Conditions promoting Rosellinia necatrix growth and infection on potted apple seedlings. A, Area under the disease progress curve (AUDPC) values (calculated on percentage of dead plants) under different conditions of temperature, soil moisture, and amendments. B, $R$. necatrix mycelium ( $\mathrm{mg} / \mathrm{g}$ soil) measured by real-time quantitative polymerase chain reaction for the different treatments. Different letters within each panel denote significant differences according to the Tukey's test at $\alpha=0.05$. Error bars indicate the standard error of the mean.

\section{Discussion}

The ISSR molecular markers and mycelial compatibility revealed polymorphisms, as reported by López et al. (2008) and Armengol et al. (2010), among the 35 isolates of $R$. necatrix collected from infected apple trees in the northeast of Italy. These polymorphisms among isolates confirm the high level of intraspecific heterogeneity of $R$. necatrix observed previously on fruit crops (Aimi et al. 2002; Arakawa et al. 2002; Ikeda et al. 2005; López et al. 2008; PérezJiménez et al. 2002). Because of the lack of correlations of ISSR marker with geographical origin, cultivar, or nursery of origin, we conclude that white root rot in sampled apple orchards originated from multiple preexisting sources of $R$. necatrix inoculum. Among orchards, isolates were all different and, within the same orchard, isolates differed from patch to patch. In the latter case, we conclude that multiple sources of inoculum can exist within the same orchard, from which distinct patches of diseased plants have expanded over time. In some orchards, the same strain of $R$. necatrix was found at different points or in unclear patches. In this case, orchards may have been subjected to agronomic practices that spread the pathogen to new sites. It is known that the disease frequently arises in soils cropped previously to susceptible hosts (López-Herrera and Zea Bonilla 2007; Pliego et al. 2012). In northern Italy, first reports of white root rot on apple trees occurred in the 1980s, when new orchards were established, replacing other crops (grapevine or pear) or forest.
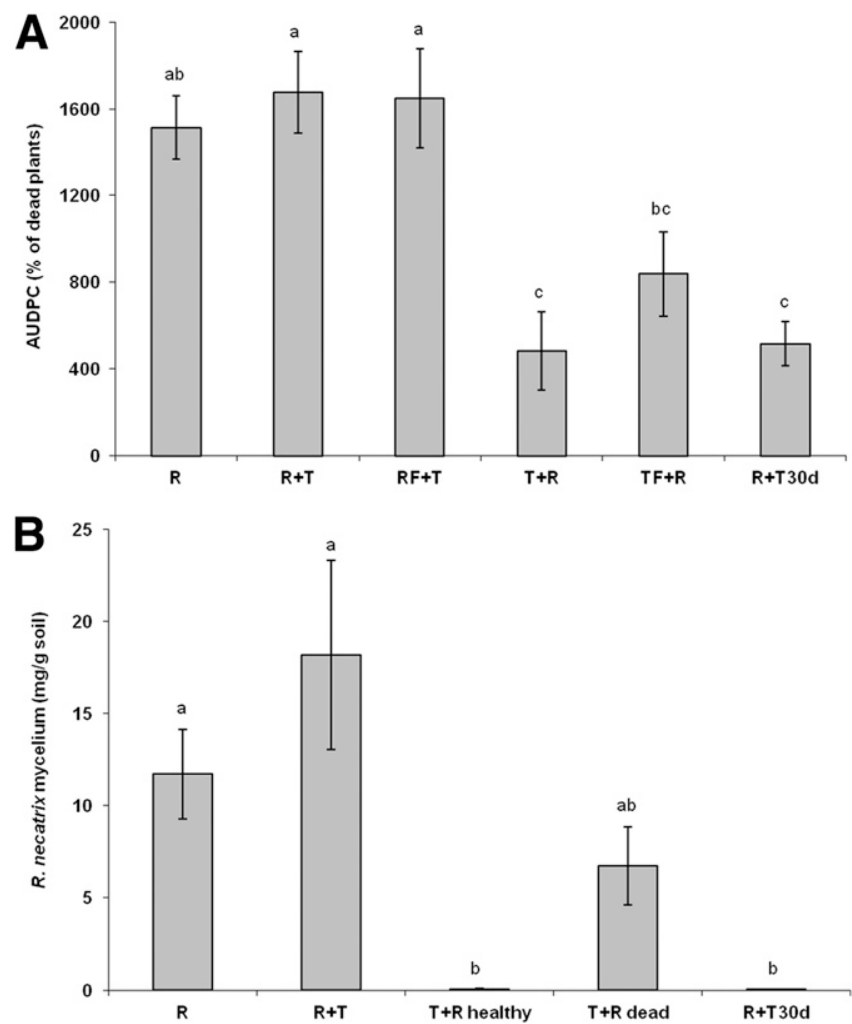

Fig. 3. Biocontrol experiments and quantification of Trichoderma atroviride SC1 and Rosellinia necatrix in soil. A, Area under the disease progress curve (AUDPC) values (calculated on percentage of dead plants) for the different biocontrol treatments: $\mathrm{R}=R$. necatrix-positive control; $\mathrm{R}+\mathrm{T}=T$. atroviride $\mathrm{SC} 1$ applied 1 week after pathogen inoculation; $R F+T=T$. atroviride SC1 applied 1 week after pathogen inoculation and the addition to soil of milled shrimp shells; $T+R=T$. atroviride SC1 applied 1 week before pathogen inoculation; $T F+R=T$. atroviride SC1 and milled shrimp shells applied 1 week before pathogen inoculation; and $\mathrm{R}+\mathrm{T} 30 \mathrm{~d}=T$. atroviride SC1 applied at the same time of $R$. necatrix, 30 days before transplanting apple seedlings. B, $R$. necatrix mycelium ( $\mathrm{mg} / \mathrm{g}$ soil) measured by real-time quantitative polymerase chain reaction in different biocontrol treatments ( $T+R$ healthy and $T+R$ dead refer to soil samples collected from pots of the $T+R$ treatment containing healthy and dead plants, respectively). Different letters within each chart denote significant differences according to the Tukey's test at $\alpha=0.05$. Lines drawn through tops of bars represent \pm one standard error of the mean. 
Indeed, all infected apple orchards in our survey succeeded hosts of $R$. necatrix. For this reason, it is crucial, before replanting an orchard, to exclude the presence of the disease in the previous crop. If the orchard is planted after forest, attention should be paid to the roots of the wild plant species, because it was recently demonstrated they can act as potential inoculum reservoirs of white root rot (Takemoto et al. 2014). All of the surveyed orchards were planted into a sandy or sandy-loam soil and the presence of white root rot in apple orchards cultivated in heavier soils was not observed. That this is type of soil seems to favor growth of $R$. necatrix is also shown by white root rot incidence on poplar biology (Anselmi and Giorcelli 1990). In fact, $R$. necatrix prefers well-aerated soils, and soil with low oxygen content negatively affects the development and occurrence of the disease (Pérez-Jiménez 2006). Because it is quite difficult to control soil conditions in the field, in this study, the experiments to evaluate the role of environmental factors in promoting white root rot were carried out on apple plants under controlled conditions. Soil water content and temperature were confirmed as the main factors influencing mycelial development and, consequently, infections of white root rot on apple seedlings, as seen in a few other crops. Where the optimal conditions of soil humidity and temperature (field capacity and $25^{\circ} \mathrm{C}$ ) for $R$. necatrix development occurred, the addition of humified organic matter increased disease severity. The effect of organic matter on $R$. necatrix aggressiveness was also demonstrated by Carlucci et al. (2013), where the forest soil, rich in organic matter, showed high disease incidence compared with soils collected from agricultural sites. In contrast, the wood fragments added to the soil to simulate the incorporation of pruning wood material did not increase the mortality of plants due to $R$. necatrix infections. Perhaps because the pathogen takes a long time to colonize wood residues, our trials did not adequately address the long-term effect of incorporating pruning wood debris in the soil.

We found a high and positive correlation between plant mortality and the amount of $R$. necatrix mycelium in the soil. This is in agreement with the finding in poplar plantlets grown in pots of Anselmi and Giorcelli (1990), who showed that the incidence of dead plants was related to the quantity of initial inoculum. These results could be a key point in finding new tools for control of the disease. Reducing mycelium content in infected soils below a certain threshold (i.e., with agronomical practices and antagonist organisms) could have important consequences on the rate of $R$. necatrix infections.

The careful removal of infected roots and plant residues, rotation with nonhost species (e.g., cereals), or leaving the land uncultivated for 2 to 4 years are the only available methods for reducing the pathogen inoculum before replanting a new orchard (Schena et al. 2008). However, such practices often are not feasible due to the nature of the landscape (e.g., when orchards are grown on the slopes of hills they cannot easily be cultivated with other crops), the infrastructure (e.g., the presence of hail protection nets), and economic constraints (e.g., the value of the land is too high to permit it to be left uncultivated). Microbial biocontrol agents offer a low-impact solution compared with chemical fumigants and have been receiving increasing interest in recent years. Our experiments confirmed, under controlled conditions, the ability of $T$. atroviride $\mathrm{SC} 1$ to reduce white root rot incidence on apple seedlings. On the other hand, our results also demonstrated that the efficacy of $T$. atroviride $\mathrm{SC} 1$ strongly depends on the timing of its application. T. atroviride SC1 has its highest efficacy when applied 1 week before $R$. necatrix inoculation and the planting of the apple plants, demonstrating the need to develop and colonize the soil before the arrival of the pathogen. T. atroviride SC1 was also effective when applied together with $R$. necatrix inoculum 30 days before planting. When T. atroviride $\mathrm{SC} 1$ was applied before $R$. necatrix inoculum or with the pathogen 30 days before planting, the amount of $R$. necatrix mycelium was found to be very low or even undetectable at the end of the experiment, confirming that reducing the quantity of inoculum is crucial for the control of white root rot. These results indicate that $T$. atroviride $\mathrm{SC} 1$ requires a certain period of time to be able to decrease the inoculum and, consequently, the incidence of $R$. necatrix.
Based on this observation, we suggest that application of T. atroviride $\mathrm{SC} 1$ in the field should occur in late summer to early autumn, when the temperature of the soil is still sufficiently high for some weeks to allow $T$. atroviride $\mathrm{SC} 1$ growth, with the new orchard planted the following spring. Although $T$. atroviride $\mathrm{SC} 1$ seems to be a good candidate for the biological control of white root rot in apple orchards, further studies of $T$. atroviride $\mathrm{SC} 1$ applications in infected orchards will be necessary to confirm our findings and verify the biocontrol efficacy of this strain under field conditions.

This is the first study extensively addressing the problem of white root $R$. necatrix on apple tree with the aim of finding practical solutions. Evaluation of the impact of certain environmental factors and agronomic practices, including biocontrol, has increased knowledge of the disease on apple and provided insight into approaches to prevention of this disease. Assessment of pathogen infestations at the time of orchard establishment is important to minimizing this disease. Biocontrol with $T$. atroviride $\mathrm{SC} 1$ seems to be a promising instrument, while further studies should focus on finding the best schedule of application under field conditions for the best $R$. necatrix inoculum reduction.

\section{Acknowledgments}

We thank S. Di Lenarda and R. Osler (University of Udine) for providing Rosellinia samples and information on orchards of the Friuli Venezia Giulia region and for all their cooperation; F. Garcia-Figueres (Laboratori de Sanitat Vegetal, Generalitat de Catalunya, Barcelona, Spain) for providing the two $R$. necatrix isolates used as references; D. Bertoldi and G. Toller (Centre for Technology Transfer, FEM) for soil analysis; A. Colombini, A. Chiusole, D. Ress, and C. Sicher for help in the trials; and the advisors of Unità Frutticoltura FEM for support in monitoring and sampling. This research was supported by the European Community's Seventh Framework Programme (FP7/2007-2013) under grant agreement number 265865PURE.

\section{Literature Cited}

Aimi, T., Yotsutani, Y., and Morinaga, T. 2002. Vegetative incompatibility in the ascomycete Rosellinia necatrix studied by fluorescence microscopy. J. Basic Microbiol. 42:147-155

Anselmi, N., and Giorcelli, A. 1990. Factors influencing the incidence of Rosellinia necatrix Prill in poplar. Eur. J. For. Pathol. 20:175-183.

Arakawa, M., Nakamura, H., and Uetake, Y. 2002. Presence and distribution of double-stranded RNA elements in the white root rot fungus Rosellinia necatrix. Mycoscience 43:21-26.

Armengol, J., Vicent, A., Leon, M., Berbegal, M., Abad-Campos, P., and GarciaJimenez, J. 2010. Analysis of population structure of Rosellinia necatrix on Cyperus esculentus by mycelial compatibility and inter-simple sequence repeats (ISSR). Plant Pathol. 59:179-185.

Campbell, C. L., and Madden, L. V. 1990. Introduction to Plant Disease Epidemiology. John Wiley and Sons, New York.

Carlucci, A., Manici, L. M., Colatruglio, L., Caputo, A., and Frisullo, S. 2013. Rosellinia necatrix attack according to soil features in the Mediterranean environment. For. Pathol. 43:12-18.

Chini, C. and de Clauser, R. 1983. Osservazioni e rilievi della presenza dei marciumi radicali nel Trentino. Giornate Frutticole 1983:47-55.

Colatruglio, L., Camele, I., Raimondo, M. L., Carlucci, A., Lops, F., Marcone, C., and Frisullo, S. 2006. Molecular characterization of Rosellinia necatrix isolates in southern Italy. In: 12th Cong. Mediterr. Phytopathol. Rhodes Island, Greece.

Dice, L. R. 1945. Measures of ecologic association between species. Ecology 26: 297-302.

Faretra, F., and Frisullo, S. 2002. Rosellinia root rot. Pages 6-7 in: Compendium of Nut Crop Diseases, Temperate Zones. B. L. Teviotdale, T. J. Michailides, and J. W. Pscheidt, eds. American Phytopathological Society, St Paul, MN.

Francis, S. M. 1985. Rosellinia necatrix-Fact or fiction? Sydowia 38:75-86.

Freeman, S., Sztejnberg, A., and Chet, I. 1986. Evaluation of Trichoderma as a biocontrol agent for Rosellinia necatrix. Plant Soil 94:163-170.

Freeman, S., Sztejnberg, A., Shabi, E., and Katan, J. 1990. Long-term effect of soil solarization for the control of Rosellinia necatrix in apple. Crop Prot. 9:312-316.

Ikeda, K., Nakamura, H., and Matsumoto, N. 2005. Comparison between Rosellinia necatrix isolates from soil and diseased roots in terms of hypovirulence. FEMS Microbiol. Ecol. 54:307-315.

Khan, A. H. 1959. Biology and pathogenicity of Rosellinia necatrix (Hart.) Berl Biol. (Lahore Pak.) 5:199-245.

Longa, C. M. O., Savazzini, F., Tosi, S., Elad, Y., and Pertot, I. 2009. Evaluating the survival and environmental fate of the biocontrol agent Trichoderma atroviride SC1 in vineyards in northern Italy. J. Appl. Microbiol. 106: 1549-1557.

López, M., Ruano-Rosa, D., López-Herrera, C. J. M., and Hermosa, R. 2008 Intraspecific diversity within avocado field isolates of Rosellinia necatrix from south-east Spain. Eur. J. Plant Pathol. 121:201-205. 
López-Herrera, C. J. 1998. Hongos de Suelo en el Cultivo del Aguacate (Persea Americana Mill) del Litoral Andaluz. V Jornadas Andaluzas de Frutos Tropicales Seville: CAP. Congresos Jornadas 47/98:139-152.

López-Herrera, C. J., Pérez-Jiménez, R. M., Basallote-Ureba, M. J., Zea-Bonilla, T., and Melero-Vara, J. M. 1999. Loss of viability of Dematophora necatrix in solarised soils. Eur. J. Plant Pathol. 105:571-576.

López-Herrera, C. J., and Zea Bonilla, T. 2007. Effects of benomyl, carbendazim, fluazinam and thiophanate methyl on white root rot of avocado. Crop Prot. 26: 1186-1192.

Makambila, C. 1978. Morphogenése des Rosellinia. Phyton 36:25-30.

Makambila, C., Larpent, J. P., and Guillaumin, J. J. 1976. Light and the growth of thalli of two fungi of the genus Rosellinia. Phyton 34:179-184.

Mantell, S. H., and Wheeler, B. E. J. 1973. Rosellinia and white root rot of Narcissus in the Scilly isles. Trans. Br. Mycol. Soc. 60:23, IN1-35.

Nakamura, H., Uetake, Y., Arakawa, M., Okabe, I., and Matsumoto, N. 2000. Observations on the teleomorph of the white root rot fungus, Rosellinia necatrix, and a related fungus, Rosellinia Aquila. Mycoscience 41:503-507.

Pellegrini, A., Prodorutti, D., and Pertot, I. 2014. Use of bark mulch pre-inoculated with Trichoderma atroviride to control Armillaria root rot. Crop Prot. 64:104-109.

Pérez-Jiménez, R. M. 2006. A review of the biology and pathogenicity of Rosellinia necatrix - The cause of white root rot disease of fruit trees and other plants. J. Phytopathol. 154:257-266.

Pérez-Jiménez, R. M., Jiménez-Diaz, R. M., and López-Herrera, C. 2002. Somatic incompatibility of Rosellinia necatrix on avocado plants in southern Spain. Mycol. Res. 106:239-244.

Pertot, I., Longa, C. M. O., Savazzini, F., Prodorutti, D., and Michelon, L. 2008. Trichoderma atroviride SC1 for biocontrol of fungal diseases in plants. Patent WO 2009116106 A1.

Pliego, C., Kanematsu, K., Ruano-Rosa, D., De Vicente, A., López-Herrera, C., Cazorla, F. M., and Ramos, C. 2009. GFP sheds light on the infection process of avocado roots by Rosellinia necatrix. Fungal Genet. Biol. 46:137-145.

Pliego, C., López-Herrera, C., Ramos, C., and Cazorla, F. M. 2012. Developing tools to unravel the biological secrets of Rosellinia necatrix, an emergent threat to woody crops. Mol. Plant Pathol. 13:226-239.
Ruano-Rosa, D., Cazorla, F. M., Bonilla, N., Martin-Pérez, R., De Vicente, A., and López-Herrera, C. J. 2014. Biological control of avocado white root rot with combined applications of Trichoderma spp. and rhizobacteria. Eur. J. Plant Pathol. 138:751-762

Ruano-Rosa, D., and López Herrera, C. J. 2009. Evaluation of Trichoderma spp. as biocontrol agents against avocado white root rot. Biol. Control 51:66-71.

Ruano-Rosa, D., Schena, L., Ippolito, A., and López-Herrera, C. J. 2007. Comparison of conventional and molecular methods for the detection of Rosellinia necatrix in avocado orchards in southern Spain. Plant Pathol. 56: 251-256.

Savazzini, F., Longa, C. M. O., Pertot, I., and Gessler, C. 2008. Real-time PCR for detection and quantification of the biocontrol agent Trichoderma atroviride strain SC1 in soil. J. Microbiol. Methods 73:185-194.

Schena, L., and Ippolito, A. 2003. Rapid and sensitive detection of Rosellinia necatrix in roots and soils by real time Scorpion PCR. J. Plant Pathol. 85:15-25.

Schena, L., Nigro, F., and Ippolito, A. 2002. Identification and detection of Rosellinia necatrix by conventional and real-time Scorpion-PCR. Eur. J. Plant Pathol. 108:355-366.

Schena, L., Nigro, F., and Ippolito, A. 2008. Integrated management of Rosellinia necatrix root rot on fruit tree crops. Pages 137-158 in: Integrated Management of Plant Pests and Diseases. A. Ciancio and K. G. Mukerji, eds. Springer eBook, Dordrecht, The Netherlands.

Sztejnberg, A. 1990. Rosellinia (Dematophora) root rot. Pages 46-47 in: Compendium of Apple and Pear Diseases. A. L. Jones and H. S. Aldwinkle, eds. American Phytopathological Society, St. Paul, MN.

Sztejnberg, A., Freeman, S., Chet, I., and Katan, J. 1987. Control of Rosellinia necatrix in soil and in orchards by solarization and Trichoderma harzianum. Plant Dis. 71:365-369.

Takemoto, S., Nakamura, H., and Tabata, M. 2014. The importance of wild plant species as potential inoculum reservoirs of white root rot disease. For. Pathol. 44:75-81.

Tourvieille de Labrouhe, D. 1982. Pénétration de Rosellinia necatrix (Hart.). Berl. dans les racines du pommier en conditions de contamination artificielle. Agronomie 2:553-560. 